\title{
Characterisation of High Abrasion Resistant Commercial Glazes
}

\author{
A. TUNAli* \\ Eczacibasi Building Products Co. VitrA Innovation Center Bozuyuk/Bilecik-Turkey
}

\begin{abstract}
In recent years high-abrasion resistance became industrially important for floor and porcelain tiles. Abrasive wear mechanism of commercial ceramic glazes were investigated by Scanning Electron Microscope, X-ray diffraction (XRD) and abrasion test using the PEI-visual evaluation technique. The study shows that anorthite is the main phase of commercial glazes, accompanied with quartz and corundum, and its properties are not good enough for high resistance. It is also observed that when mean free path of the anorthite phase decreases the wear resistance increases.
\end{abstract}

DOI: 10.12693 /APhysPolA.127.1243

PACS: $81.05 . \mathrm{Mh}$

\section{Introduction}

The materials used in several building applications, such as ceramic tiles or glass mosaic need to have working surfaces characterized by very high abrasion resistance. Abrasion is one of the most frequent wear mechanisms on the surface of ceramic materials. It is defined as material pull-out caused by the action of hard particles, spread freely on the surface of the material that is being subjected to abrasive wear or between two surfaces that are in relative movement. It is well known as pull-out and cracks are able to strongly decrease both the mechanical performances, in particular hardness and wear resistance and the aesthetic, loss of brightness, discolouration effects, material removal. Besides, the presence of cracks and areas from which the material was removed, increasing the surface roughness, favours storage of powders and other dirty agents, preventing an efficient cleaning action [1-3]. Studies carried out on ceramic tiles in recent years in order to offer a solution to this problem focus on increasing mechanical and abrasion resistance $[4-6]$. However, no information regarding the industrial application of the study results has been provided.

The aim of our study is to analyze industrial glazes which are stated to have high abrasion resistance and are commercially used, and thus to determine the effect of the type, form, and distribution of crystalline phase on the abrasion resistance of glass-ceramic glazes. Hence, it is aimed to conduct a study to shed light on glassceramic glaze development studies for achieving glassceramic glazes with high abrasion resistance in compliance with fast firing conditions.

\section{Materials and method}

First, floor tile glaze (YK1) and two types of commercial porcelain tile glazes (PT1 and PT2) are supplied in powder form. For glaze preparation, in the light

\footnotetext{
*e-mail: ayse.tunali@eczacibasi.com.tr
}

of industrial recipes, suitable amounts of powder, carboxyl methyl cellulose (CMC), sodium tripolyphosphate (STPP) and water were mixed in a ball mill for 15 min. The floor tile glaze slurry and porcelain tile glaze slurries were afterwards applied to pre-engobed green floor tile and porcelain tile bodies respectively supplied by Vitra Karo San. A.S. of Turkiye. The previously dried glazed floor tile was fired at $1190{ }^{\circ} \mathrm{C}$ for 28 minutes and dried glazed porcelain tiles were fired at $1220{ }^{\circ} \mathrm{C}$ for 38 minutes in the industrial roller furnace in Vitra Tiles Incorparation.

The colour values $L^{*}, a^{*}$, and $b^{*}$ of all fired tiles were measured using a Minolta CR-300 series chroma meter. Gloss was determined with gloss meter (Minolta Gloss 268) with a $60^{\circ}$ light incident angle and roughness was measured with surface roughness tester (Ceramic Instruments S.r.l, KR100) on the glaze surface. The scratch hardness of surface was determined according to the mohs scale. The abrasion resistance was determined according to the EN-ISO 1545-7 standard (PEI method).

The crystalline phases present in the glazes were identified by XRD (Rigaku Rint 2000 series diffractometer with $\mathrm{Cu} \mathrm{K}$ radiation). The microstructure of the crystallized glaze samples was studied by scanning electron microscopy (SEM, SUPRA 50VP at $20 \mathrm{kV}$ ), fitted with an EDX.

\section{Results and discussion}

No maturation problem or glaze defect has been observed subsequent to fast firing cycle in commercial YK1 glaze applied on floor tile and PK1 and PK2 glazes applied on porcelain tile surfaces. The quality of glaze depends on the aesthetic characteristics, as well as mechanical properties, such as scratching and abrasion resistance. Therefore, color, brightness, and roughness values of the surfaces have been measured, together with PEI rating and Mohs hardness values (Table I).

When the results are interpreted, PK2 glaze, $L^{*}$ value of which is the lowest, is the most transparent glaze while PK1 glaze is the most opaque one. As expected, YK1 glaze, which has the lowest roughness value, has 
higher brightness than the others. On the other hand, PK2 glaze, which has the highest roughness value, is the most opaque glaze. The best glaze is PK1 glaze in terms of scratching and abrasion resistance in accordance with Mohs hardness and PEI rating.

TABLE I

Colour $\left(L^{*}, a^{*}, b^{*}\right)$, gloss $\left(60^{\circ}\right)$, roughness, hardness and wear resistance values of the selected glazes.

\begin{tabular}{c|c|c|c|c|c|c|c}
\hline \hline Glazes & $L^{*}$ & $a^{*}$ & $b^{*}$ & $\begin{array}{c}\text { Gloss } \\
\left(60^{\circ}\right)\end{array}$ & $\begin{array}{c}\text { Rough- } \\
\text { ness }\end{array}$ & $\begin{array}{c}\text { Hard- } \\
\text { ness }\end{array}$ & $\begin{array}{c}\text { Wear } \\
\text { resistance }\end{array}$ \\
\hline PK1 & 81.92 & 0.63 & 6.75 & 4.7 & 9.45 & 9 & 5 \\
\hline PK2 & 72.14 & 0.54 & 2.74 & 4 & 9.96 & 8 & 4 \\
\hline YK1 & 77.88 & 0.22 & 2.07 & 14 & 5.94 & 7 & 4
\end{tabular}

Figure 1 exhibits the XRD patterns of the phases present in the characterized glazes. Anorthite, corundum and quartz crystals have been detected in all of the three glazes having been analyzed. In general, quartz and corundum are added into the glaze as raw material in order to increase the hardness of the glaze in glaze production. However, anorthite crystalline phase is thought to be formed during firing cycle in the glassy melt.

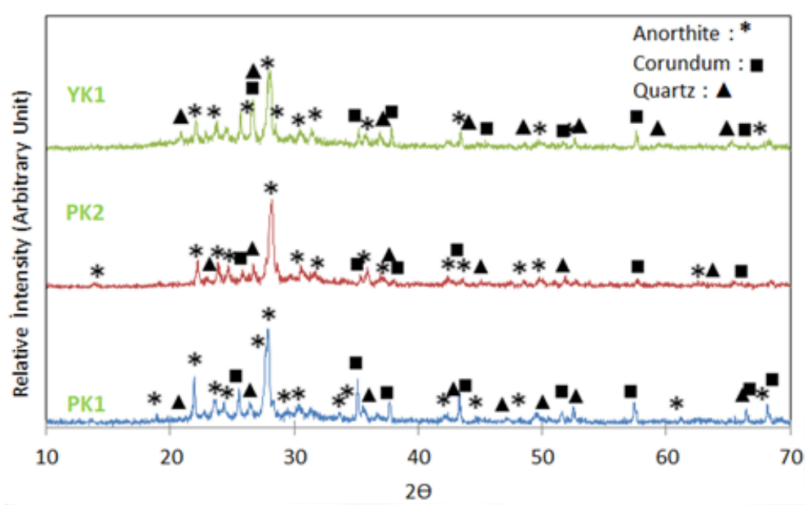

Fig. 1. XRD pattern of the YK1, PK1 and PK2 glazes.

Cross-sectional views (Fig. 2a) of the glazes having been analyzed and the detailed views in the enlarged images are given in Fig. 2b. When the overall views (Fig. 2a) are assessed, it can be said that the reason why PK1 glaze looks more opaque than the other glazes is that it comprises high amount of pore and crystal. In the views (Fig. 2b) of enlarged images, on the other hand, it is observed that only glassy phase is present in some parts of YK1 glaze. In Fig. 1, in XRD pattern, wide peak elevation in the area where $2 \Theta$ value is $20-40$ for YK1 glaze, has confirmed glassy phase areas in microstructure views.

Because the same crystals have been detected in each three glazes, only EDX results of YK1 have been presented here. The results of EDX analysis (Fig. 3) carried out for the crystals shown on the enlarged images of YK1 glaze have shown that anorthite (Fig. 3a), quartz (Fig. 3b) and corundum (Fig. 3c) crystals detected over the glaze surface in XRD are distributed along the cross section. Moreover, metastable plagioclase (Fig. 3d) phase has also been detected in glazes. (a)

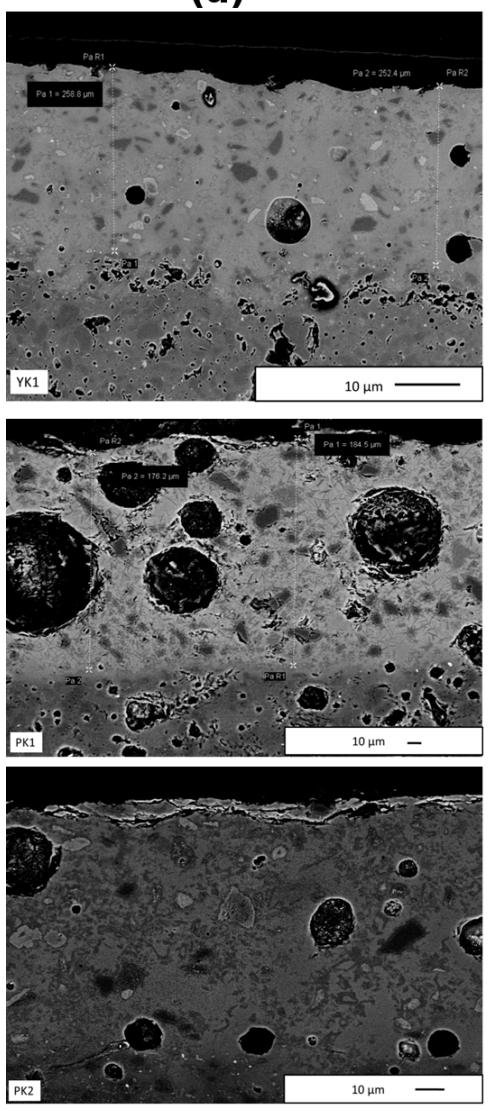

(b)
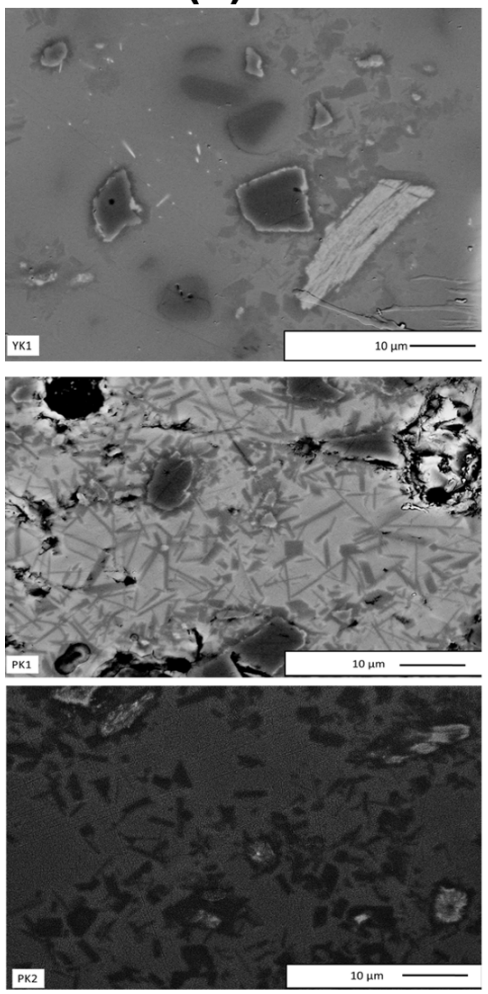

Fig. 2. SEM micrographs of the YK1, PK1, PK2 glazes showing a) general and b) detailed microstructural views. 
(a)

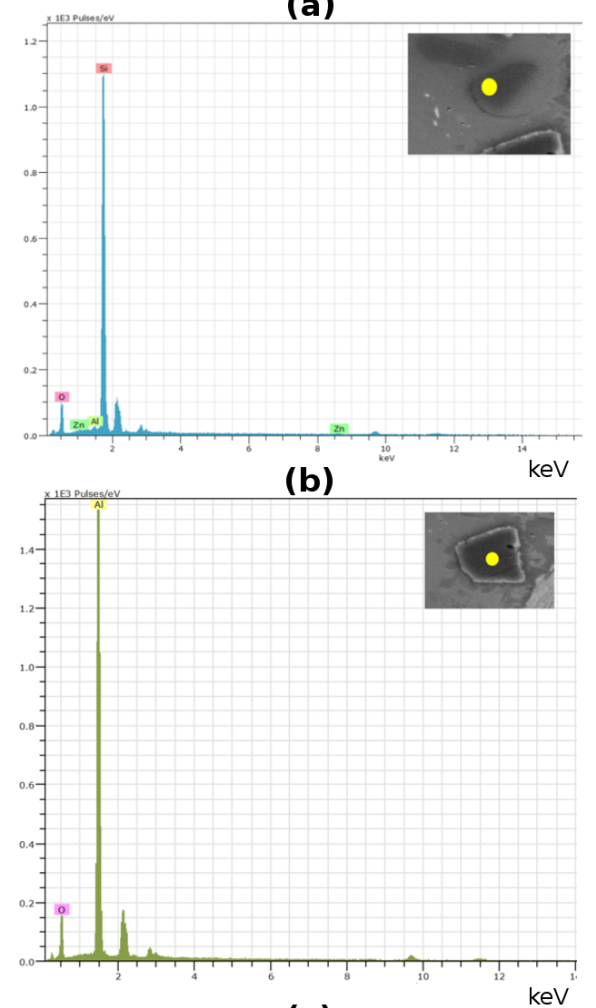

(c)
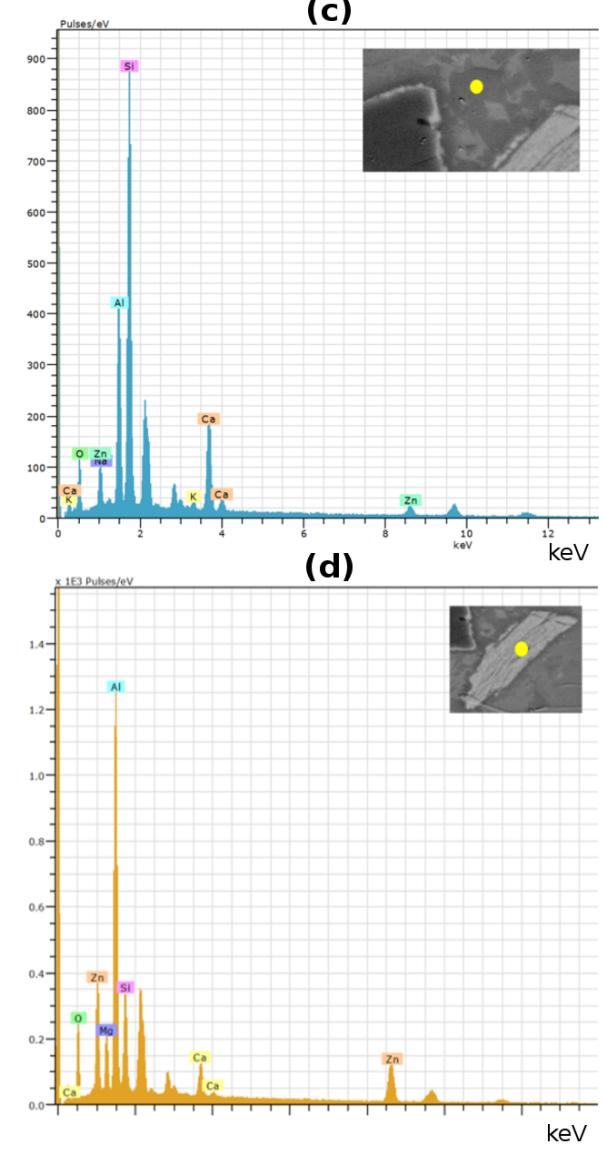

Fig. 3. EDX analyses of the crystals in the spots marked by $\bullet$ symbols.
Anorthite crystals detected in YK1 glaze are in contact with one another and they are not separated in clear crystal particles. (Figs. 2 and 3a). Low crystal amount of the former has caused it to have lower hardness value than PK1 and PK2 glazes. Abrasion value, on the other hand, is lower than that of PK1 glaze. Anorthite crystals are needle-like in PK1 glaze (Fig. 2) and they are homogeneously distributed in the glaze. In cross-sectional view of the PK1 glaze, it is seen that corundum and quartz crystals are also distributed densely and homogeneously, in addition to anorthite crystals. The presence of dense and homogeneous crystals increases the hardness and abrasion resistance of PK1 glaze. Abrasion resistance increases as the mean free path between crystals decreases. In PK2 glaze, however, anorthite crystals are distributed homogeneously in rod-like manner, albeit not in a clear needle-like manner as in PK1 glaze. This microstructure has caused it to have lower hardness and abrasion resistance values than PK1 glaze.

\section{Conclusion}

Floor tile and porcelain tile glass-ceramic glazes stated to have high abrasion resistance and supplied from different companies have been analyzed. It has been found that all of the glazes comprise anorthite, corundum and quartz crystals, in addition to glassy phase; and that they comprise plagioclase phase only in the interior sections thereof. It has been seen that although glass-ceramic glazes have similar crystalline phases, their physical and mechanical properties differ from one another. Abrasion and scratching resistances of the glaze increase as the mean free path between crystals decreases. Furthermore, it has also been found that densely distributed needle-like anorthite crystals increase the abrasion resistance of the glaze.

It has been also concluded that abrasion resistance of most of the commercial glazes is not sufficient with this rate (PEI; 4) and wear resistance should be increased by studying new glass-ceramic systems.

\section{References}

[1] A.G. Evans, D.B. Marshall, Wear Mechanisms in Ceramics "Fundamentals of Friction and Wear of Material", Ed. D.A. Rigney, American Society for Metals, Metals Park, Ohio 44073, p.439 1981.

[2] M.J. Ibáñez, J. Gilabert, M. Vicent, P. Gómez, D.Muñoz, Wear 267, 2048 (2009).

[3] J.M. Hutchings, Tribology: Friction and Wear of Engineering Materials, Edward Arnold, London 1992.

[4] D. Herman, T. Okupski, W. Walkowiak, J. Eur. Ceram. Soc. 31, 485 (2011).

[5] B.E. Yekta, P. Alizadeh, L. Rezazadeh, J. Eur. Ceram. Soc. 26, 3809 (2006).

[6] B. Mirhadi, B. Mehdikhani, N. Askari, Solid State Sci. 14, 430 (2012). 